\title{
TYPOLOGICAL CLASSIFICATION AND OBSERVED DAMAGE PATTERNS OF MASONRY CHURCHES AFTER THE 2016 CENTRAL ITALY EARTHQUAKE
}

\author{
G. CIANCHINO ${ }^{1}$, G. DE MATTEIS ${ }^{2}$ AND G. BRANDO $^{1 *}$ \\ ${ }^{1}$ Department of Engineering and Geology, \\ University "G. d'Annunzio" of Chieti Pescara, Pescara, Italy \\ e-mail: giorgia.cianchino@unich.it, \\ gbrando@unich.it (*corresponding author) \\ ${ }^{2}$ Department of Architecture and Industrial Design, \\ University of Campania "Luigi Vanvitelli", Aversa, Italy \\ email: gianfranco.dematteis@unicampania.it
}

Keywords: Historical Structures, Masonry Churches, Cultural Heritage, Damage Probability Matrices, Damage Scenarios, 2016 Central Italy Earthquake.

\begin{abstract}
The seismic protection of cultural heritage is an important topic that has been faced by several researchers in the last decades. Seismic events of the past have highlighted the need of achieving a proper knowledge of the vulnerability of cultural heritage, in particular of churches, in order to put in the field proper mitigation measures at the large scale. According to this premise, this paper deals with the damage scenario observed on eighty seven churches hit by the 2016 Central Italy earthquake. In a first stage, the most important structural features of the studied churches are discussed and threated by the statistical standpoint. The reported information have been collected through the A-DC form, adopted by the Civil Protection Department and by the Ministry of Heritage and Cultural Activity and Tourism (MiBACT), which was used in the framing of the damage reconnaissance activity carried out by the ReLUIS Italian consortium in the aftermath of the earthquake. Also, the form has been used in order assess the damage of each macro-element and, then, to assign a damage index to each church. The presented work is framed in a wider research activity that aims at providing a predictive methodology for the vulnerability assessment of churches at the regional scale. This methodology was already calibrated on the basis of the 2009 L'Aquila seismic event. The outcomes presented in this paper will serve to further prove the reliability of the proposed model.
\end{abstract}

\section{INTRODUCTION}

The last seismic sequence that hit the central regions of Italy began the $24^{\text {th }}$ August 2016, with an event of magnitude 6.0 MW occurred in Amatrice and Accumuli (in the district of Rieti). Then, it had its peak the $30^{\text {th }}$ October, with epicenter in Norcia, in the district of Perugia, when a magnitude of $6.5 \mathrm{MW}$ was reached. The whole seismic sequence affected 1200 square kilometers in the central Apennines and included the Regions of Abruzzi, Lazio, Marche and Umbria, as it is shown in Figure 1 when the affected areas and the epicenters are shown. 


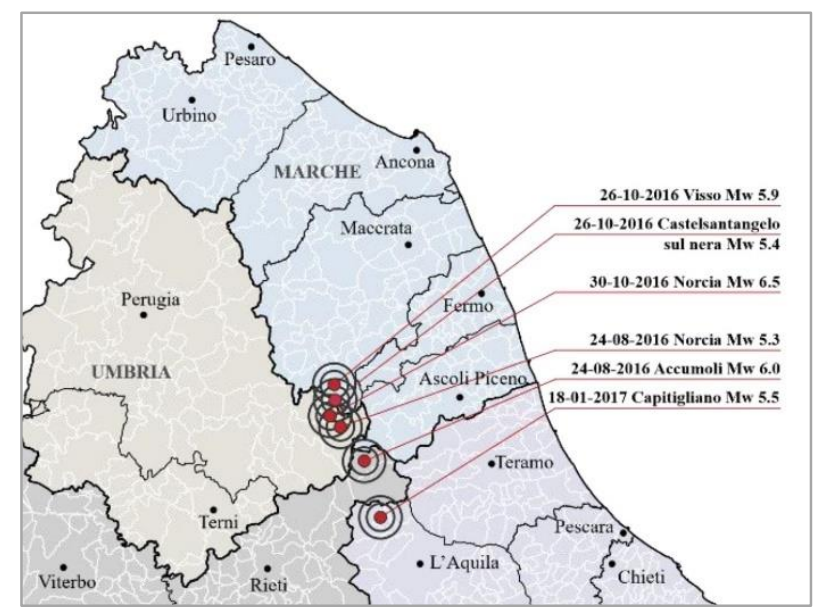

Figure 1: Seismic sequence of Central Italy earthquake

Since the first shock it was immediately clear that the earthquake was capable to produce devastating scenarios. In fact, 299 deaths and more than 300 injuries were registered, with the destruction of entire municipalities such as Accumuli, Amatrice and Arquata del Tronto. Fortunately, the following earthquakes did not provoke analogous quantities of deaths and injuries, as people were properly dislocated, but several buildings in the affected urban centers collapsed.

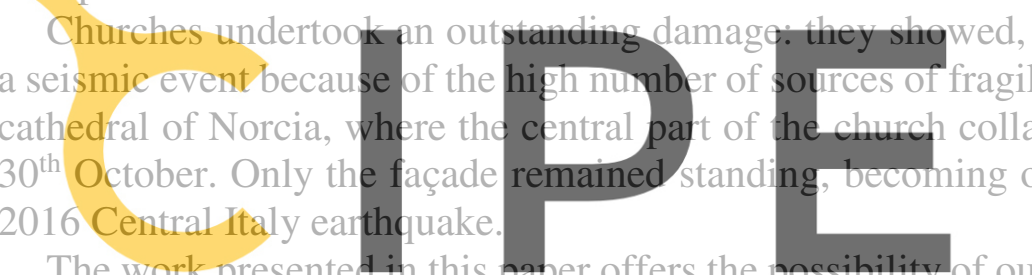

The work presented in this paper offers the

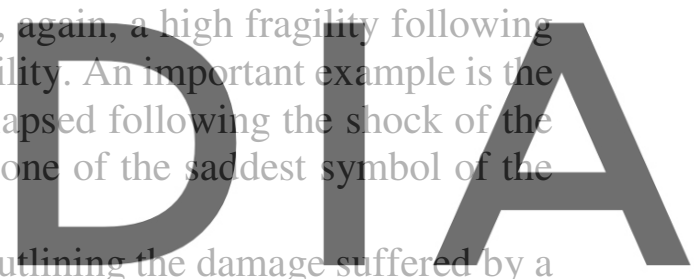
group of 87 churches affected by the 2016 earthquake. This damage was analyzed following


Protection and of the Ministry of Cultural Heritage, through the application of the "A-DC" form. The latter was used for emergency management purpose after the earthquake, with the aim of evaluating the accessibility of Cultural Heritage.

The paper is articulated as follows. In Section 2, the seismicity of the area is briefly shown; next the group of churches dealt with in the paper, as well as their characteristics, are described. Then (Section 3) the damage scenario is analyzed by comparing the formulation of the A-DC forms and the methodology proposed by the Cultural Heritage Guidelines. Finally, a statistical analysis of the damage undertook by both the whole churches and the single macro-elements is presented.

\section{HISTORICAL SEISMICITY OF THE ANALYZED AREA}

The 2016 Central Italy earthquake hit an area characterized by a relevant historic seismicity [1][2][3]. In the core of the "seismic crater" (the area hit by the earthquake appointed by the Italian government for economical support) the strongest event occurred in the 18th century, during the 1703 earthquakes in Valnerina and L'Aquila (Magnitude 6.7 Mw). These earthquakes were really devastating and caused tens of thousands of victims overall [4]. The 
Amatrice area suffered 4 strong historical earthquakes: those are the earthquake of 1627, with the epicenter in Accumuli (5.3 MW), the earthquake of 1639 with epicenter in Amatrice (6.2 MW), the earthquake of 1646 with epicenter in Monti della Laga (5.9 MW) and the earthquake occurred in 1672 with the epicenter in Amatrice (5.3 MW). In the southern area of the crater, affected by the seismic event of the $18^{\text {th }}$ January, the most historically important events are those deriving from the Abruzzo area: in 1619 in the L'Aquila area, magnitude 5.3 MW, in 1950 in the Teramo area, magnitudo 5.7 MW and in the 2009, again in the L'Aquila area.

\section{THE STUDIED CHURCHES}

87 churches located in the area affected by the earthquake have been inspected by the authors. For this analysis, the "A-DC" form, proposed by the Ministry of Cultural Heritage, was used. This form allows to evaluate the state of usability of the churches according to the severity of the collapse mechanisms activated by the earthquake on the single macro elements.

The considered churches were built at very different times, with a minimal prevalence of 17th century buildings (18\%). They are distributed in the three regions of Abruzzi (70\%), Lazio $(15 \%)$ and Marche (15\%), with a larger distribution in the provinces of Teramo (Abruzzi) and Ascoli Piceno (Marche). Overall the churches present features that are typical of the Apennine areas.

The analyzed churches are often characterized by very regular plants. As shown in Figure $2 \mathrm{a}, 79 \%$ has a single rectangular nave, $5 \%$ has two naves and the remaining $16 \%$ is made of a three naves plant.

\section{Most of the}

characterized by a sing

example of the typology shown in Figure, $2 b$.
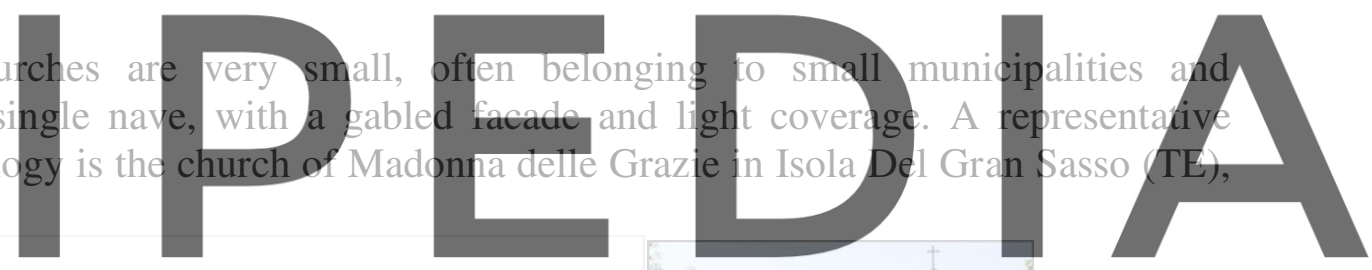

$100 \%$

Register for free at https\%/www.scipedia.com to download the version without the watermark
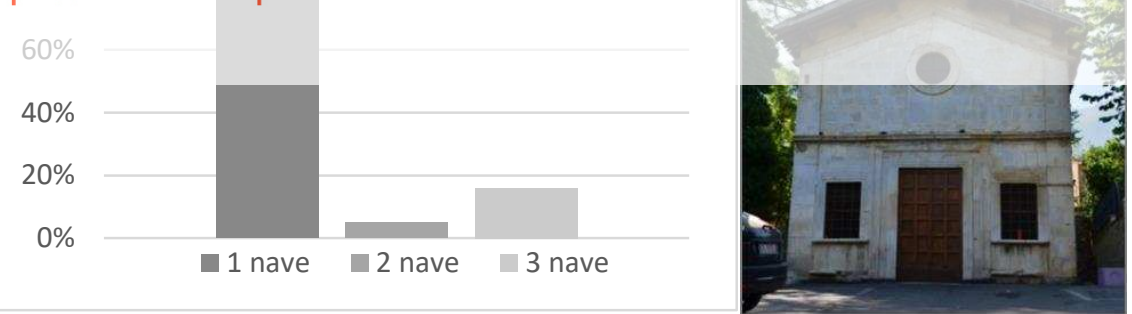

Figure 2: a) Typological distribution of churches; b) Madonna delle Grazie church in Isola del Gran Sasso (TE).

The analysis highlighted the different types of facades, with a predominance of gable façades $(51 \%)$ and a minority made of façades enclosed within two towers $(1 \%)$, as shown in figure 3.

In figure $4 \mathrm{a}$ the frequencies of the observed types of bell tower is shown. A prevalence of bell gables and tower bells (almost $40 \%$ each) has been revealed; cell bell tower have been observed for the $10 \%$ of the cases, whereas, for the remaining $10 \%$ no bell towers have been observed.

The presence of the other architectural elements that generally characterize churches with huge dimensions, such as transepts, domes and chapels, have been found seldom. In particular, 
the transept is present only in $2 \%$ of cases, the dome in $6 \%$, the chapels in $21 \%$. The results are summarized in Figure 4b.
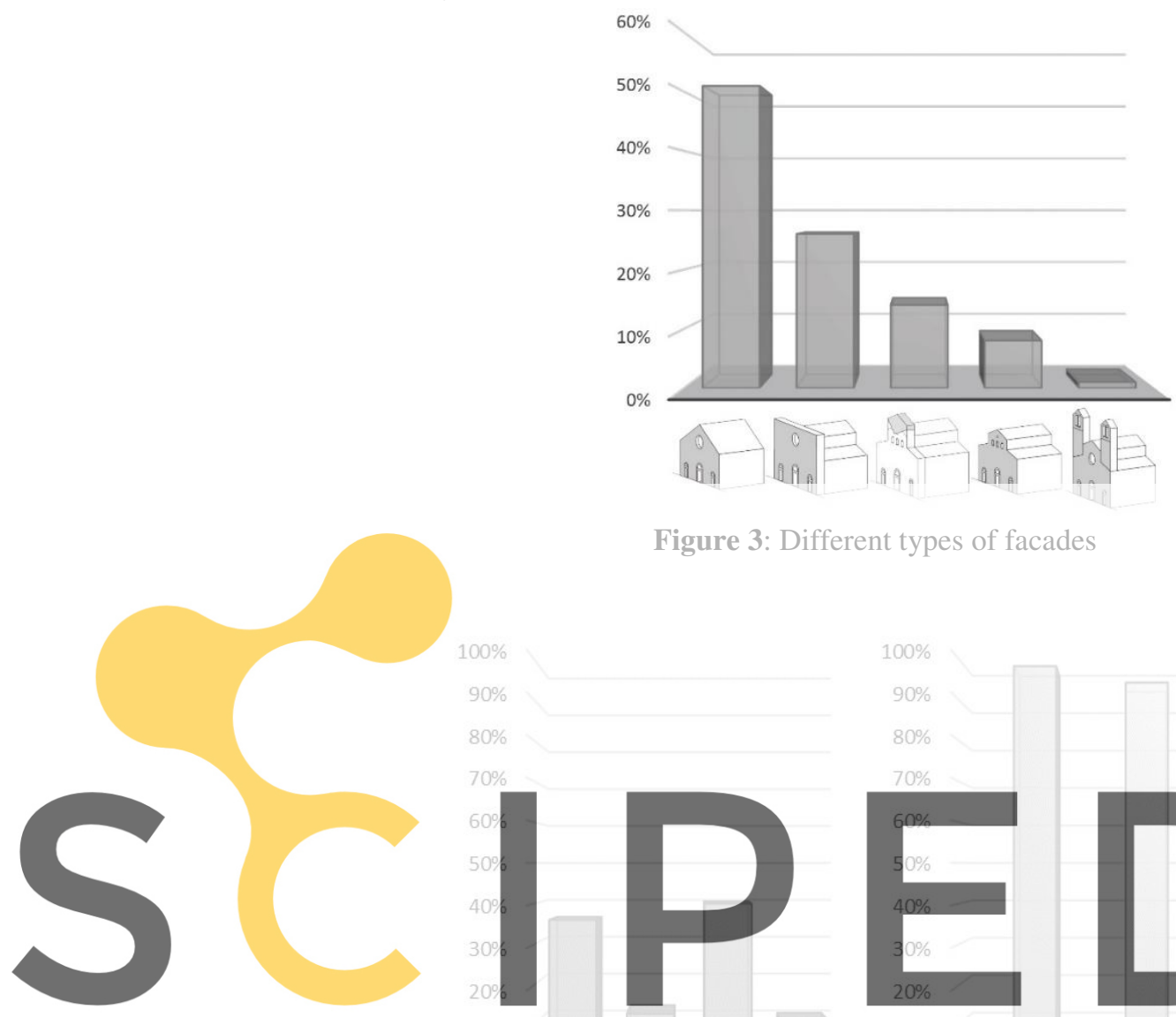

Figure 3: Different types of facades

Register for free at https//wWW.scipedia.com to downhoad the version without the watermark

Figure 4: a) Type of bell tower b) Presence/absence of the macroelements transept, dome and chapels

The $39 \%$ of churches present vaulted roofs. However, it should be considered that a substantial number of churches (36\%), have wooden cover. The remaining churches $(24 \%)$ have flat roof, and the $1 \%$ have present steel roofs that, evidently, were added recently.

\section{DAMAGE ANALYSIS}

\subsection{Damage analysis according to the A-DC form}

The damage analysis was carried out by collecting the information given by the A-DC form. The form defines 28 potential collapse mechanisms, according to the Cultural Heritage Guidelines (2010) [5]. These are listed in table 1.

or each mechanism, a judgment on the severity of the damage provoked by the earthquake was given. This judgment consisted in a score $d_{k}$ ranging from $k=0$ to $k=5$ and increasing with the severity of damage ( $d_{0}=0$ in case of absent mechanism, $d_{5}=5$ for mechanisms associated to collapse of the macroelement) . 
Table 1. The 28 mechanisms considered by the A-DC form

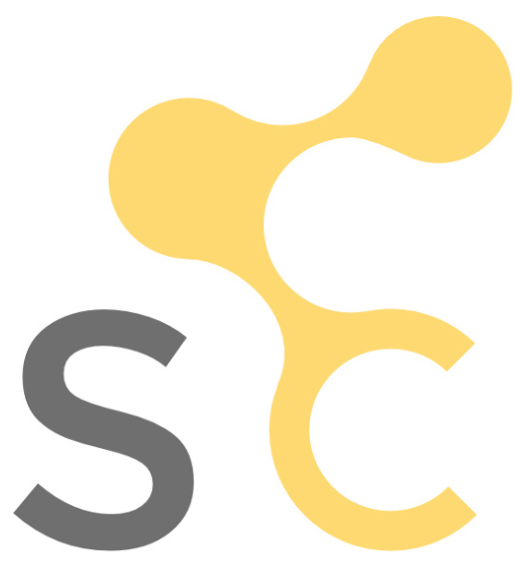

\begin{tabular}{|c|c|c|}
\hline$m$ & mechanism & $\rho_{m}$ \\
\hline 1. & Façade overturning; & 1 \\
\hline 2. & Mechanism at the top façade & 1 \\
\hline 3. & Mechanism in plane of façade & 0.5 \\
\hline 4. & Narthex & 0.25 \\
\hline 5. & Transversal response & 1 \\
\hline 6. & Shear mechanism lateral walls & 1 \\
\hline 7. & Longitudinal response & 1 \\
\hline 8. & Central nave vaults & 1 \\
\hline 9. & Aisles vaults & 0.75 \\
\hline 10. & Transept façade overturning & 0.75 \\
\hline 11. & Shear mechanism in transept & 0.5 \\
\hline 12. & Transept vaults & 0.75 \\
\hline 13. & Triumphal arches & 1 \\
\hline 14. & Dome & 0.75 \\
\hline 15. & Lantern & 0.25 \\
\hline 16. & Apse overturning & 0.75 \\
\hline 17. & Shear mechanism in apse & 0.5 \\
\hline 18. & Apse vaults & 1 \\
\hline 19. & Mechanism in roof of the nave & 0.5 \\
\hline 20. & Mechanism in roof of transept & 0.5 \\
\hline 21. & Mechanism in roof of apse & 0.5 \\
\hline 22. & Chapeloverturning & 0.25 \\
\hline 23. & Shear medhanisı in chapels & 0.25 \\
\hline 24. & Chapel vaults & 0,5 \\
\hline 25. & Plan-height irregularity & 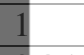 \\
\hline 26. & Architectural detail & 0.25 \\
\hline 27. & Bell tower & 1 \\
\hline 28. & Bell cell & 0.5 \\
\hline
\end{tabular}

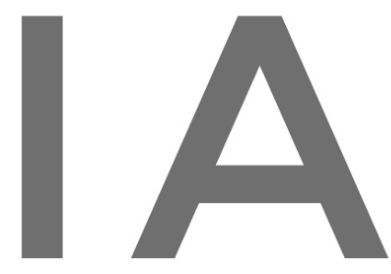

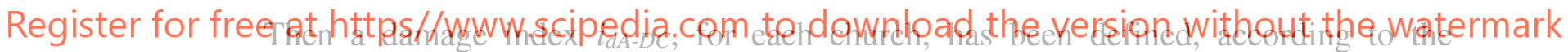

expression eq(1).

$$
i_{d A-D C}=\frac{\sum_{m=1}^{n} d_{k, m}}{5 \cdot n}
$$

where $m$ is a generic mechanism to which the score $d_{k, m}$ is associated and $n$ is the number of possible mechanisms that are present in the analysed church.

\subsection{Damage analysis according to Cultural Heritage Guidelines}

The procedure described in Section 4.1, used for the purpose of defining an immediate judgment for accessibility on the churches during the reconnaissance activity, does not actually take into due account that the different collapse mechanisms may have a different importance to the for the purpose of global stability. To take this into account, a second analysis was conducted using the indications of the Guidelines on Cultural Heritage (2010) that associate to the generic mechanism $m$ a weight factors $\rho_{m}$ to be introduced in the formulation of the damage index $i_{d}$ expressed in eq. (1), which is modified as reported in eq. (2). 


$$
i_{d \text { Guid }}=\frac{1}{5} \cdot \frac{\sum_{m=1}^{n} \rho_{m} \cdot d_{k, m}}{\sum_{m=1}^{n} \rho_{m}}
$$

The $\rho_{m}$ factor is 0 when the mechanisms that cannot be activated in the church due to the absence of the macroelement, while it ranges between 0.5 and 1 in the other cases [6]. The considered values of $\rho_{m}$, as indicated in [7], are given in Table 1.

\subsection{Damage levels for the whole churches}

The damage indices, obtained for each church by applying both the two procedures described above, were used to define a global damage level $D_{k}$, variable from 0 to $5\left(D_{0}=0, D_{1}=1 \ldots D_{5}\right.$ $=5$ ) according to criteria defined in the literature by Lagomasino and Podestà (2004) [8].The criteria are summarized in table 2.

Table 2: Relation between the damage index $i_{d}$ and the global damage level $D_{k}$, according to [8]

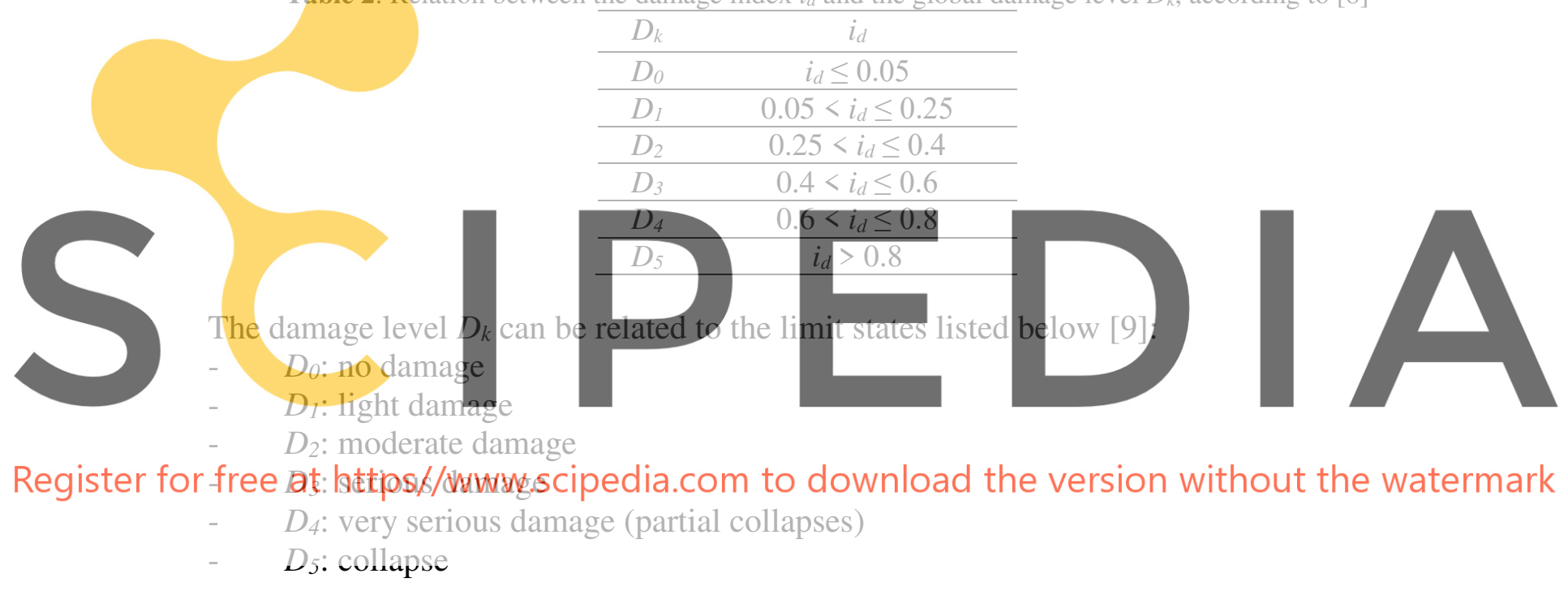

They are schematically represented in Figure 5.



$D_{k}=1$



$D_{k}=2$

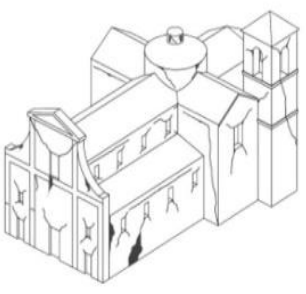

$D_{k}=3$

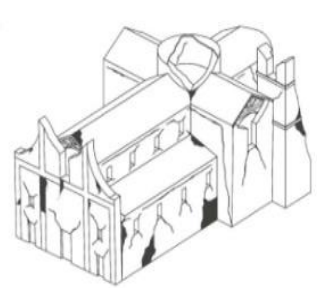

$D_{k}=4$

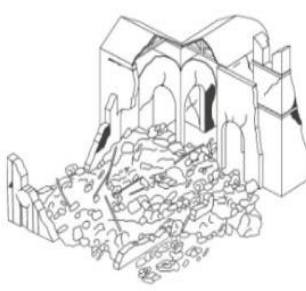

$D_{k}=5$

Figure 5: Limit states corresponding to the five damage levels $D_{k}$

The obtained $D_{k}$, obtained according to the two procedures discussed in Section 4.1 and 4.2, are reported in Figure 6 (organized in two graphs arranged on two rows). As it is possible to observe, the two procedures give almost the same results except for six cases. 

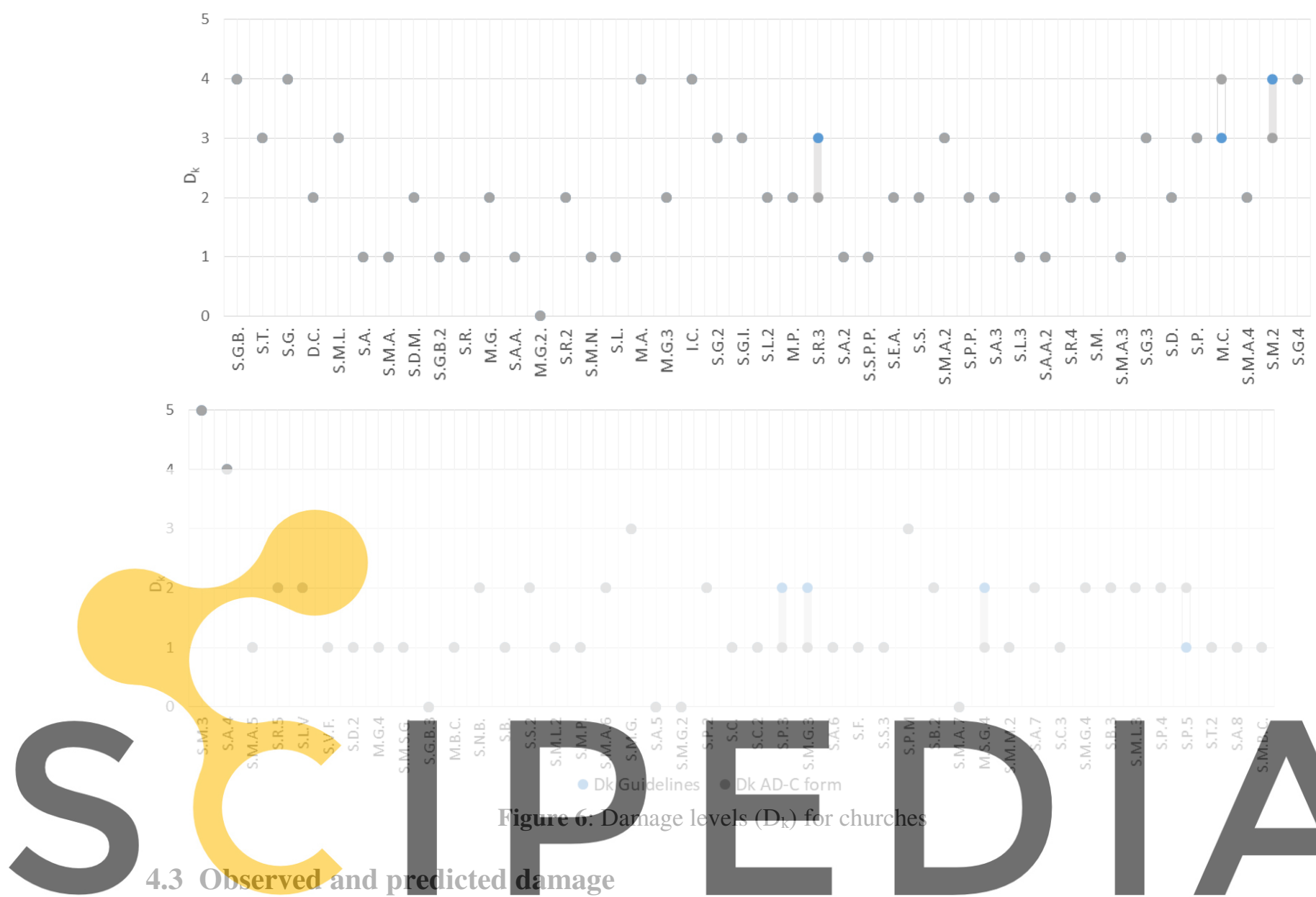

4.3 Observed and predicted damage
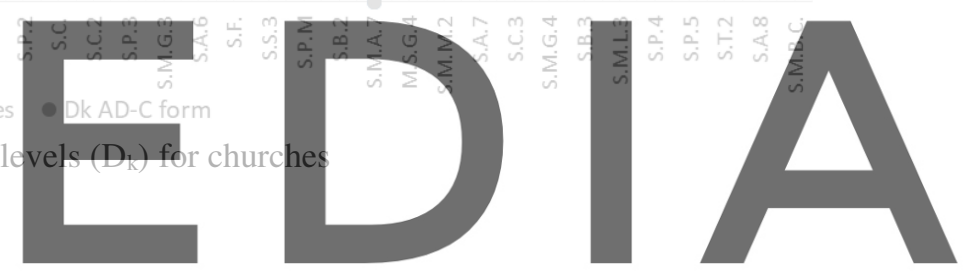

The elaboration of the frequencies of the obtained $D_{k}$ evaluated for the studied 87 churches

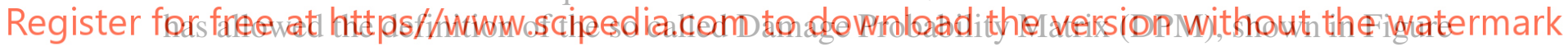

7 , which is as a useful tool for representing the occurred damage scenario.

It must be pointed out that the conducted analysis concerns a very large territory, with macroseismic intensity varying between IV and VII measured in the MCS scale. For this reason, the proposed DPM can be intended, in a predictive key, as a tool for the evaluation of the vulnerability of the churches at regional scale. This evaluation can be generally applied also to other territories presenting churches with the same features of the here analysed ones.

Always in Figure 7, it is possible to observe that the gathered frequencies could have been predicted by applying the binomial probability distribution (DPF) provided in eq. (3), once that the mean damage $\mu_{D}$ had been assessed.

$$
p_{k}=\frac{5 !}{k ! \cdot(5-k) !} \cdot\left(\frac{\mu_{D}}{5}\right)^{k} \cdot\left(1-\frac{\mu_{D}}{5}\right)^{5-}
$$

where

$$
\mu_{D}=\frac{\sum_{i=1}^{\kappa} D_{\kappa}}{\kappa}
$$


Being $\kappa$ the number of analyzed churches.

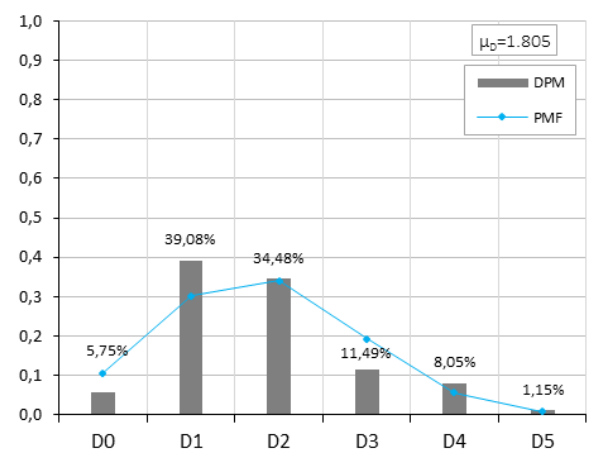

Figure 7: Damage Probability Matrix (DPM) of the analyzed churches

This result confirms what has been found by other studied related to Italian churches hit by earthquakes of the past (see, for example, [10]).

\subsection{Macroelement analysis}

The most important damages observed during the inspection in the churches were mostly related to mechanisms involving the facades and roofing system in the central nave. Significant damage levels were also found on the bell towers and gables.

With reference to fa churches presented dam the $7 \%$ damage $D_{4}$ and was found in the Church of Santa Giuste in Cortino (TE), which facade plan to which damage D4 has been attributed (Figure 8a).

Many of the out-of-plane mechanisms occured in the presence of poor masonty. This is the case of the church of San Michele in Valle Castellana (TE), which showed a collapse of a Register for fire at thet contributed to the delamination of the external material (Figure 8b).
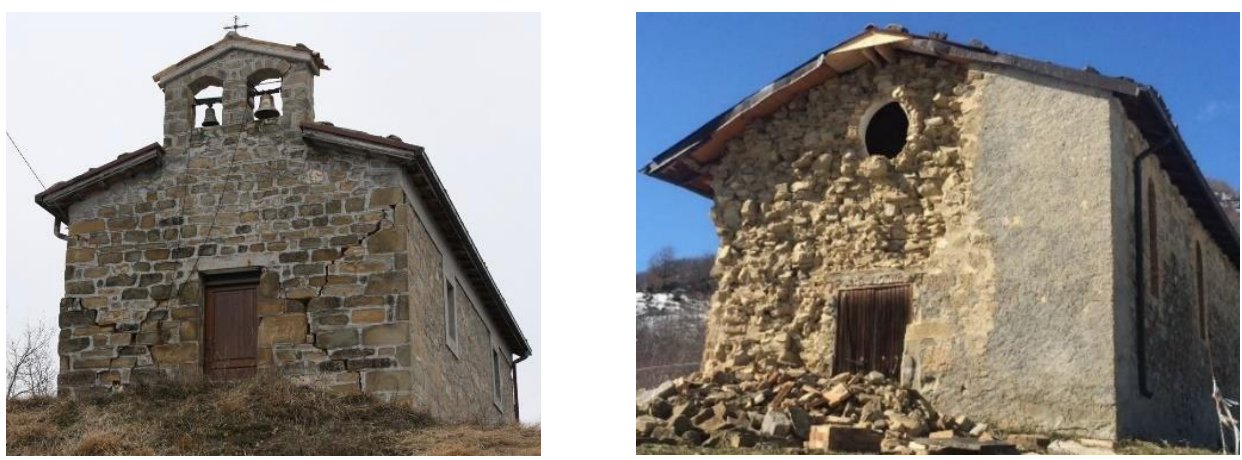

Figure 8: a) Santa Giusta church in Cortino (TE); b) San Michele church in Valle Castellana (TE)

It is important to note that more than half of the bell towers or gables resulted seriously damaged. These are slender elements, which often do not present any type of anti-seismic devices. Therefore important damages and, in some cases, collapses have been observed. An example is the bell gable of the church of San Paolo in Cortino (TE), where a partial collapse 
was found (Figure 9).

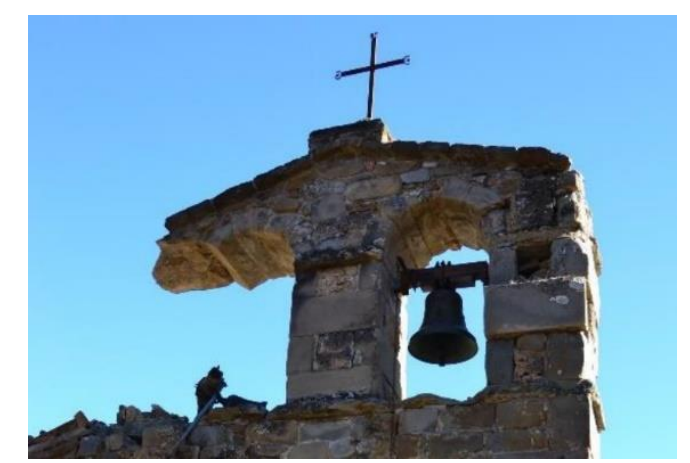

Figure 9: The damaged bell gable of San Paolo a Cortino (TE)

The damage analysis was also carried out for all the other macroelements. The data have been gathered according to the observed mechanisms listed in Table 1 and organized as listed below:

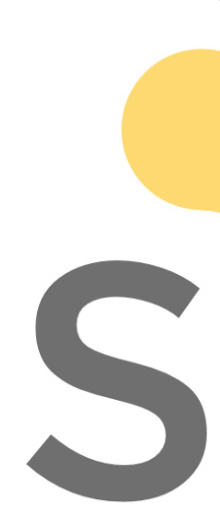

Out of plane (mechanisms number 1-10-16)

Facade (mechanisms number 2-3-4)

Lateral walls (mechanisms number 6-11-17-25)

Chapels (mechanisms number 22-23)

Columns (mechanism number 7)

Dome (mechanisms number 14 15)

Roofing system

Bell tower/gab

Arches and v

Decorations
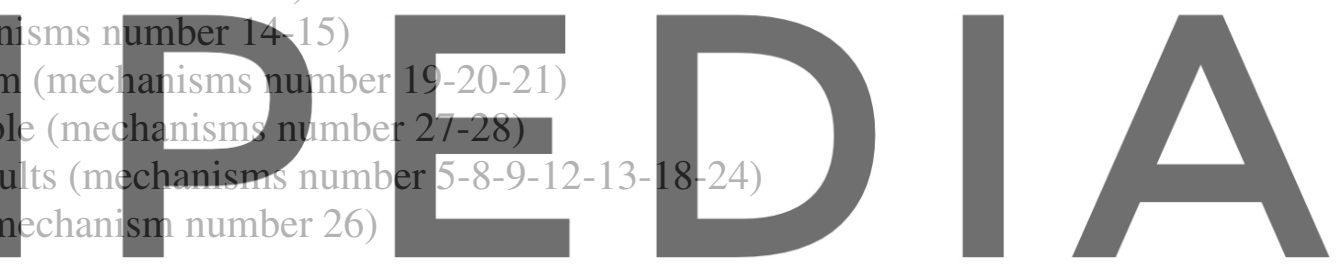

The frequencies of the reported damage are shown in Figure 10. It is interesting to note that,

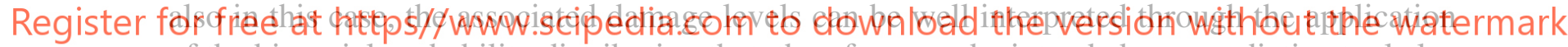

of the binomial probability distribution that, therefore, can be intended as a predictive tool also

when the prevision is carried out on the single mechanisms involving the single macroelements.

This result confirm what was found in [12] by the Authors with reference to the churches in Abruzzi hit by the 2009 L'Aquila earthquake.

\section{CONCLUSIONS}

In this paper an extensive analyses of the damage observed on 87 churches hit by the 2016 Central Italy earthquake has been proposed. The main results can be summarized as follows:

- In the analyzed stock, mainly composed by small churches with a single nave and a rectangular plan, the higher damage was observed on the façade and on the bell towers/gables;

- The observed damage scenario has been represented in terms of Damage Probability Matrix (DPM) and the gathered frequencies have been interpreted by means of the binomial probability distribution that proved to be reliable in reproducing the observed scenario once that the mean damage is known; 


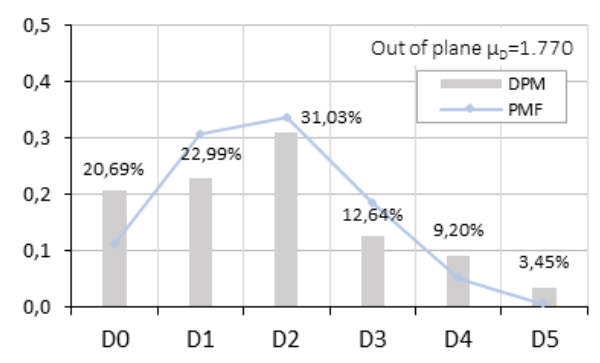

a)

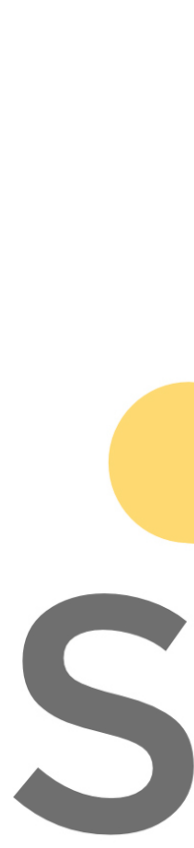

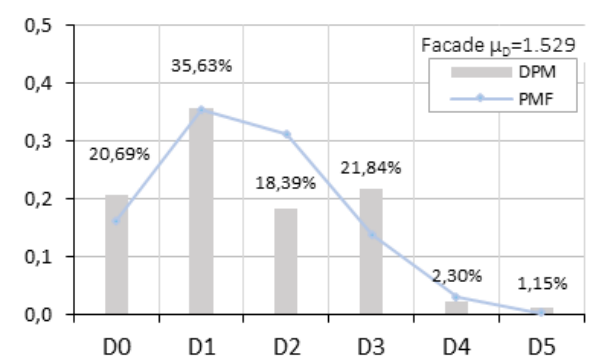

b)

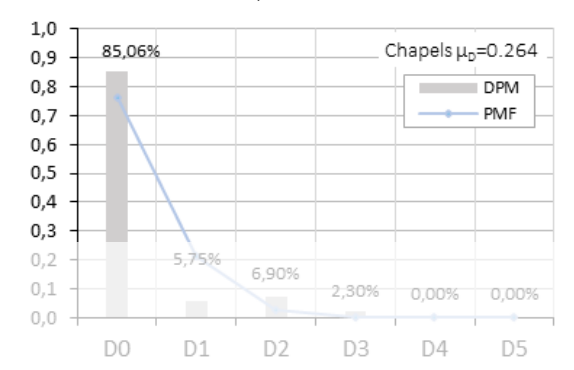

d)

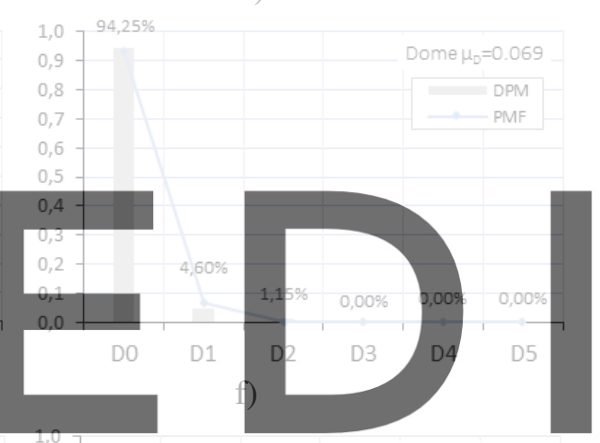

Register for free at https//www.scipedia.com to download the version without the watermark

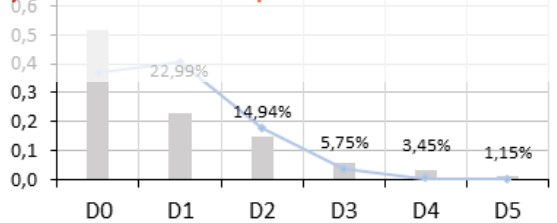

g)

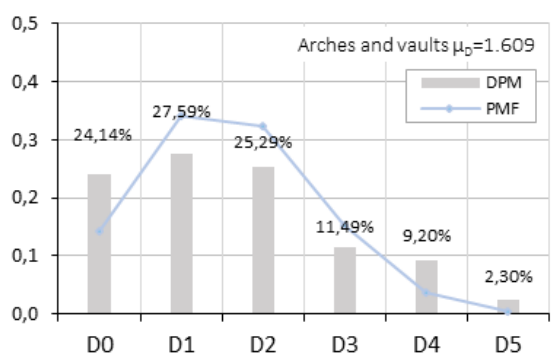

i)

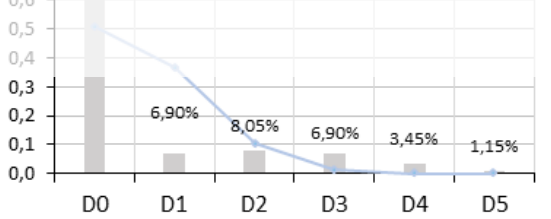

h)

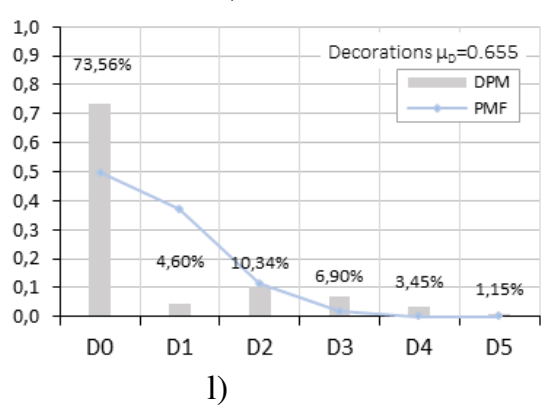

Figure 11: Statistical analysis of damage by macroelements with probabilistic interpretation according to binomial distribution (a) Out of plane, (b) Facade, (c) Lateral wall, (d) Chapels, (e) Column, (f) Dome, (g) Coverage, (h) Bell tower, (i) Arches and vaults, (l) Decorations. 
- As already discussed in previous studies carried out by the authors, DPMs are an effective tool also to interpret the damage provoked by mechanisms involving single macroelements.

Acknowledgements. This study has been developed within the Italian research Project ReLuis. The reconnaissance activities have been carried out by the authors with the technicians of the Ministry of Cultural Heritage (MIBACT). A part of the presented study has been extracted from the graduation thesis of Dr. Cristina Schiavi.

\section{REFERENCES}

[1] Gruppo di Lavoro INGV sul terremoto in centro Italia, 2016. Rapporto di sintesi sul Terremoto in centro Italia Mw 6.5 del 30 ottobre 2016, [DOI: 10.5281/zenodo.166019].

[2] Gruppo di lavoro INGV 2017. "Relazione sullo stato delle conoscenze sulla sequenza sismica in centro italia 2016-2017 (Aggiornamento Al 2 Febbraio 2017)." 2017.

[3] Gruppo di lavoro INGV. 2016. "Second Summary Report of the Ml 6.0 Amatrice Earthquake of August 24, 2016 (Central Italy)." 2016.

[4] Tashkov, L., Krstevska, L., Naumovski, N., De Matteis, G., Brando, G. 2010. Ambient vibration tests on three religious buildings in Goriano Sicoli damaged during the 2009 L'Aquila earthquake COST ACTION C26: Urban Habitat Constructions under Catastrophic Events - Proceedings of the Final Conference, pp. 433-438.

[5] Linee Guida per la valutazione e riduzione del rischio sismico del patrimonio culturale allineate alle nuove Norme tecniche per le costruzioni (d.m. 14 gennaio 2008). Normativa Italiana per la protezione dei beni culturali. Ministero per i Beni e le Attività Culturali, 2010. Circolare n.26.

[6] Criber, E., Brando, G., De Matteis, G., 2015. The effects of L'Aquila earthquake on the St. Gemma church in Goriano Sicoli: part I-damage survey and kinematic analysis. Bulletin of Earthquake Engineering, 13 (12), pp. 3713-3732.

[7] De Matteis, G., Criber, E., Brando, G. 2016. Damage Probability Matrices for Three-Nave Masonry Churches in Abruzzi After the 2009 L'Aquila Earthquake. International Journal of Architectural Heritage, 10 (2-3), pp. 120-145

[8] Lagomarsino, S., Podestà, S., 2004. Seismic Vulnerability of Ancient Churches: II. Statistical Analysis of Surveyed Data and Methods for Risk Analysis. Earthquake Spectra, Volume 20, No. 2, pages 395-412, May 2004.

[9] Grunthal, G., 1998. European Macroseismic Scale. Centre Européen de Géodynamique et de Séismologie, Luxembourg; Vol. 15.

[10] De Matteis, G., Brando, G., Corlito, V., 2019. Predictive model for seismic vulnerability assessment of churches based on the 2009 L'Aquila earthquake. Bulletin of Earthquake Engineering. In press

[11] Brando, G., Criber, E., De Matteis, G. 2015.The effects of L'aquila earthquake on the St. Gemma church in Goriano Sicoli: part II-fem analysis. Bulletin of Earthquake Engineering, 13 (12), pp. 3733-3748.

[12] De Matteis, G., Criber, E., Brando, G. Damage Probability Matrices for Three-Nave Masonry Churches in Abruzzi after the 2009 LAquila Earthquake (2016) International Journal of Architectural Heritage, 10 (2-3), pp. 120-145. 